JurnalEkonomidanBisnis Islam (Journal of Islamic Economics and Business)

Volume I, Nomor2, Oktober 2016

ISSN: 2527-3434 (PRINT) - ISSN: 2527-5I43 (ONLINE)

Page: I44-I56

\title{
ANALISIS KESESUAIAN PREDIKSI KEBANGKRUTAN MODEL ALTMAN Z-SCORE, FULMER DAN SPRINGATE TERHADAP OPINI AUDITOR PADA PERUSAHAAN DELISTINGTAHUN 2015
}

\author{
Anissa AgustinaRahmadini \\ Universitas Widyatama \\ anissarahmadini@,gmail.com
}

\begin{abstract}
This research aims at bankruptcy prediction in PT. Bank Ekonomi Raharja which delisted from The Indonesia Stock Exchange and determine the level of suitability of these predictions with the auditor's opinion on the financial statements. This research is a descriptive study with a sample of companies that delisting from the stock exchange in 2015. Based on processing and analysis of financial data year 201I-2015 results obtained from three models of bankruptcy prediction Springate and Fulmer predicted PT. Bank Ekonomi Raharja went bankrupt during that period, while the method of Altman predicts PT. Bank Ekonomi Raharja are in the category of "gray area". In addition the level of agreement between the predictions of bankruptcy by the auditor's opinion is only $20 \%$, this corresponds to the condition that the company is still operating despite at delisted from the stock exchange.
\end{abstract}

Keyword: Bankruptcy, Financial Distress, Altman, Fulmer, Springate, Risk Management, Auditor's Opinion

\begin{abstract}
Abstrak-Penelitian ini bertujuan untuk memprediksi kebangkrutan pada PT. Bank Ekonomi Raharja yang di delisting dari Bursa Efek Indonesia dan mengetahui tingkat kesesuaian prediksi tersebut dengan opini auditor pada laporan keuangan. Jenis penelitian ini adalah penelitian deskriptif dengan sample perusahaan yang di delisting dari bursa efek pada tahun 20I5. Dari hasil pengolahan dan analisis data keuangan tahun 20I I-20I5 diperoleh hasil dari ketiga model prediksi kebangkrutan yaitu Fulmer dan Springate memprediksi PT. Bank Ekonomi Raharja mengalami kebangkrutan selama periode tersebut sedangkan pada metode Altman memprediksi PT. Bank Ekonomi Raharja berada pada kategori "grey area".Selain itu tingkat kesesuaian antara prediksi kebangkrutan dengan opini auditor hanya sebesar $20 \%$ hal ini sesuai dengan kondisi yang sudah di delisting dari bursa efek.
\end{abstract}

Kata Kunci: Bangkrut, Keuangan, Altman Z-Score, Fulmer, Springate, ManajemenResiko, Opini Auditor.

\section{PENDAHULUAN}

Keadaan perekonomian yang tidak stabilmembuat perusahaan harus mampu megelola sumber daya yang dimilikisecara efektif dan efisien.Salah satu penyebab perekonomian yang tidak stabil adalah karena kita memasuki era globalisasi dimana perusahaan bersaing tidak hanya dengan para pesaing lokal tetapi juga para pesaing dari luar negeri.
Hal ini berdampak pada kemampuan perusahaan dalam mempertahankan bisnisnya.

Persaingan ini tidak hanya terjadi pada perusahaan yang berskala kecil menengah tetapi juga dialami oleh perusahaan yang sudah berskala besar. Beberapa perusahaan besar yang tidak mampu menghadapi persaingan 
mengakibatkan mengalami financial distress.

Indikator perusahaan mengalami financial distress adalah delisted dari pasar modal. Perusahaan yang delisted dari Bursa Efek Indonesia merupakan perusahaan yang dihapuskan atau dikeluarkan dari daftar perusahaan yang sahamnya diperdagangkan di Bursa Efek Indonesia. Stelah perusahaan dikeluarkan dari bursa, maka semua kewajiban yang dimiliki perusahaan tersebut akan ikut terhapus, termasuk kewajiban untuk menerbitkan Laporan Keuangan. Bagi investor, perusahaan yang sudah delisted adalah identik dengan bangkrut karena mereka sudah tidak bisa lagi melakukan investasi di perusahaan tersebut. Delisting dapat dilakukan atas permintaan perusahaan yang menerbitkan saham atau atas perintah BEI. Delisting atas perintah BEI biasanya karena perusahaan tidak dapat memenuhi kewajiban dan aturan yang telah ditetapkan. (Prabowo dan Wibowo:2015)

Financial distress adalah suatu konsep luas yang terdiri dari beberapa situasi di mana suatu perusahaan mengalami masalah kesulitan keuangan. Istilah umum untuk menggambarkan situasi tersebut adalah kebangkrutan, kegagalan, ketidakmampuan melunasi hutang, default/perusahaan yang melanggar peraturan dengan kreditor dan bisa dikenakan hukuman. (Atmini dan Wuryana dalamIlmi, 2016)

Setiap perusahaan didirikan dengan tujuan menghasilkan keuntungan yang besar sehingga perusahaan dapat terus berkembang bahkan melakukan ekspansi usaha namun jika keadaan sebaliknya perusahaan terus mengalami kerugian perusahaan harus segera ditutup. Oleh karena itu penting bagi manajemen untuk dapat memprediksi lebih awal potensi kebangkrutan yang akan dialami oleh perusahaannya.

Menurut Suryanto.T

(20I4)

Prediksi ini dilakukan dengan tujuan agar perusahaan mampu menyusun strategi yang baru agar keluar dari "distress zone" jika masih memungkinkan.

Berdasarkan informasi yang diberikan oleh Bursa Efek Indonesia terdapat tiga perusahaan yang di delisting dari pasar modal pada tahun $20 I 5$ yaitu PT. Bank Ekonomi Raharja, PT. Davomas Abadi, dan PT. Unitex, Tbk. Dalam penelitian ini perusahaan yang menjadi objek penelitian adalah PT. Bank Ekonomi Raharja. Pihak Bank Ekonomi Raharja "Wahyu Adiguna, Head of Corporate Communication Bank Ekonomi Raharja mengatakan, alasannya adalah saham BAEK tidak aktif diperdagangkan di BEI. Mengutip data RTI, kepemilikan saham publik BAEK per akhir Desember 20I4 hanya I,06\%.

yang dikembangkan ke dalam beberapa model prediktor kebangkrutan seperti Altman, Fulmer, dan Springate. Penelitian sebelumnya yang dilakukan oleh Puspita dan Purnamasari (2016) menyatakan bahwa Model Altman merupakan prediktor terbaik dalam memprediksi kebangkrutan. Sedangkan dalam penelitian Mila Fatmawati (20I2) mengungkapkan bahwa Model Springate memiliki nilai lebih akurat dibandingkan Altman dan Springate.

Berdasarkan latar belakang diatas penelitian ini bertujuan untuk mengetahui prediktor delisting terbaik dengan menggunakan model Altman, 
Fulmer dan Springate dan disesuaikan dengan opini auditor pada laporan keuangan sehingga penulis mengangkat penelitian ini dengan judul "Analisis Kesesuaian Prediksi Kebangkrutan Model Altman Z-Score, Fulmer Dan SpringateTerhadapOpini Auditor Pada Perusahaan DelistingTahun 2015".

\section{RUMUSAN MASALAH}

Berdasarkan latar belakang penelitian maka rumusan masalah dalam penelitian ini adalah:

a. Bagaimana hasil prediksi kebangkrutan Model Altman, Fulmer dan Springate pada PT. Bank Ekonomi Raharja yang didelisting pada IO September 2015?

b. Apakah ada perbedaan hasil prediksi antara Model Altman, Fulmer, dan Zmijeski pada perusahaan delisting dari Bursa Efek Indonesia ?

c. Bagaimana tingkat kesesuaian prediksi kebangkrutan Model Altman, Fulmer, dan Springate dengan Opini Auditor?

\section{TUJUAN PENELITIAN}

Berdasarkan rumusan masalah maka tujuan penelitian ini adalah :

I. Untuk mengetahui hasil prediksi kebangkrutan Model Altman, Fulmer dan Zmijeswki pada PT. Bank Ekonomi Raharja yang delisting pada IO September 2015

2. Untuk mengetahui apakah ada perbedaan hasil prediksi antara
Model Altman, Fulmer, dan Zmijeski pada perusahaan delisting dari Bursa Efek Indonesia

3. Untuk mengetahui tingkat kesesuaian prediksi kebangkrutan Model Altman, Fulmer, dan Springate dengan Opini Auditor

\section{Telaah Literatur}

\section{a. Manajemen Keuangan}

Pengertian Manajemen Keuangan mengalami perkembangan mulai dari pengertian manajemen yang hanya mengutamakan aktivitas memperoleh dana saja sampai yang mengutamakan aktivitas memperoleh dan menggunakan dana serta pengelolaan terhadap aktiva.

Menurut Husnan dan Enny (2006:4) "Manajemen keuangan menyangkut kegiatan perencanaan, analisis dan pengendalian kegiatan keuangan".

Menurut Van Horne dan Wachowicz (2005:3) "Manajemen Keuangan berkaitan dengan perolehan, pendanaan, dan manajemen aktiva dengan beberapa tujuan umum sebagai latar belakangnya".

Dari beberapa definisi Manajemen Keuangan di atas dapat ditarik beberapa kesimpulan bahwa manajemen keuangan berhubungan dengan tiga aktivitas (fungsi) keputusanyaitu :

I. Keputusan investasi merupakan hal yang paling penting ketika perusahaan ingin menciptakan nilai. Hal itu dimulai dengan penetapan 
jumlah aktiva yang ingin dimiliki oleh perusahaan.

2. Keputusan pendanaan yaitu aktivitas untuk mendapatkan sumber dana baik dari sumber internal perusahaan maupun sumber eksternal perusahaan, termasuk juga politik deviden.

3. Keputusan manajemen aktiva yaitu setelah dana diperoleh dan dialokasikan dalam bentuk aktivaaktiva harus dikelola seefisien mungkin.

Secara normatif, tujuan manajemen keuangan adalah untuk maksimalisasi laba yang pada akhirnya bertujuan untuk memaksimalkan kesejahteraan pemilik perusahaan. Namun maksimalisasi laba mengandung kelemahan yaitu : penggunaan laba tidak mempertimbangkan tingkat risiko yang akan dihadapi pada investasi yang ditanam. Maksimalisasi kekayaan pemegang saham dapat dilakukan dengan memaksimumkan nilai sekarang atau present value, dengan cara tersebut keuntungan yang diharapkan pemegang saham dapat diperoleh di masa akan datang.

\section{b. Financial Distress}

Financial

Distressmerupakankondisidimanakeadaa n keuangan perusahaan sedang dalam keadaan tidak baik atau tidak sehat. Kondisi ini akan mengganggu kegiatan operasional perusahaan sehingga harus diwaspadai dan segera diberikan solusi.
MenurutRodonidan Ali dalam Bahri (2015) apabila ditinjau dari kondisi keuangan ada tiga keadaan yang menyebabkan financial distress yaitu factor ketidakcukupan modal atau kekurangan modal, besarnya beban utang dan bunga, dan menderita kerugian. Ketiga factor tersebut saling berkaitan satu dengan lainnya sehingga harus diwaspadai oleh pihak manajemen perusahaan agar terhindar dari kondisi bangkrut.

\section{c. Kebangkrutan}

Menurut Hanafi dalam Tambunan, dkk. (20I5) menyatakan "Perusahaan dapat dikatakan bangkrut apabila perusahaan itu mengalami kesulitan yang ringan (seperti masalah likuiditas) dan sampai kesulitan yang lebih serius yaitu solvable (utang lebih besar dibandingkan dengan asset)".

Menurut Brigham dan Gapenski dalam Prabowo dan Wibowo (20I5:197) mengatakan kebangkrutan dapat diartikan dalam bebrapa cara tergantung masalah yang dihadapi perusahaan :

I) Kegagalan Ekonomi :mengindikasikan bahwa pendapatan perusahaan tidak mampu menutupi biaya totalnya, termasuk biaya modal.

2) Kegagalan Usaha : digunakan untuk mengelompokkan kegiatan bisnis yang telah menghentikan operasinya kemudian berakibat kerugian bagi para kreditur.

3) Insolvensi Teknis : perusahaan dianggap mengalami insolvensi teknis 
jika tidak mampu membayar kewajiban jangka pendek pada saat jatuh tempo. Insolvensi teknis mengindikasikan tingkat likuiditas yang sangat rendah dan mungkin hanya bersifat sementara.

4) Insolvensi dalam pengertian kebangkrutan : hal ini terjadi ketika kewajiban total perusahaan melebihi total aktivanya. Kondisi ini jauh lebih serius dari insolvensi teknis dan cenderung mengarah pada likuidasi.

5) Kebangkrutan secara resmi : perusahaan ini tidak akan secara resmi dinyatakan bangkrut kecuali (I) perusahaan mengalami kebangkrutan berdasarkan kriteria yang telah dibuat oleh federal bankruptcy act (2) telah dinyatakan bangkrut oleh pengadilan.

\section{d. Model Prediksi Kebangkrutan \\ I) Altman Z Score}

Model Altman pertama kali dilakukan oleh Edward I. Altman pada tahun 1968 dengan menggunakan lima rasio keuangan. Model tersebut mengalami beberapa kali revisi namun digunakan adalah Altman Z Score untuk sektor jasa mengingat PT. Bank Ekonomi Raharja bergerak dibidang jasa perbankan. Adapun rumus yang digunakan menurut Gerald I dalam Savitri (20I4:4)adalah : pada penelitian ini Model yang

Dimana :

$\mathrm{X}_{\mathrm{I}}=$ Working Capital/Total Asset

$\mathrm{X}_{2}=$ Retained Earning/Total Asset

$\mathrm{X}_{3}=\mathrm{EBIT} /$ Total Asset

$\mathrm{X}_{4}=$ Book Value of Equity/Book

Value of Total Liabilities

Kriteria analisisnya adalah jika :

$Z \geq 2,6$ : dinyatakan Tidak Bangkrut

$\mathrm{I}, \mathrm{IO} \leq \mathrm{Z} \leq 2,6$ : dinyatakan kategori Grey Zone

$\mathrm{Z} \leq \mathrm{I}, \mathrm{IO}$ : dinyatakan kategori Bangkrut

2) Model Prediksi Fulmer

Dalam Lukman dan Ahmar (20I5:I4) Analisis kebangkrutan Fulmer (1984) menggunakan analisa step wise multiple discriminant untuk mengevaluasi mengevaluasi 40 rasio keuangan yang diaplikasikan pada sampel 60 perusahaan, 30 gagal dan 30 sukses dengan rata-rata ukuran asset perusahaan adalah $\$ 455.000$. Fulmer melaporkan 98\% akurat pada perusahaan satu tahun sebelum gagal dan $81 \%$ akurat lebih dari satu tahun sebelum kebangkrutan.

$\mathrm{H}$-Score $=5,52 \mathrm{X}_{\mathrm{I}}+0,2 \mathrm{I}_{2} \mathrm{X}_{2}+$ $0,073 \mathrm{X}_{3}+\mathrm{I}, 27 \mathrm{X}_{4}-0,12 \mathrm{X}_{5}+2,335 \mathrm{X}_{6}$ $+0,575 \mathrm{X}_{7}+1,082 \mathrm{X}_{8}+0,894 \mathrm{X}_{9}-$ 6,075

Dimana :

$\mathrm{X}_{\mathrm{I}}=$ Retained Earning $/$ Total Asset

$\mathrm{X}_{2}=$ Revenue/Total Asset

$\mathrm{X}_{3}=\mathrm{EBT} /$ Total Equity

$\mathrm{X}_{4}=$ Cash Flow from

Operation/Total

$\boldsymbol{Z}-\boldsymbol{S c}$ ore $=6,56 \mathrm{X}_{\mathrm{I}}+3,26 \mathrm{X}_{2}+$ Liabilities

$6,72 \mathrm{X}_{3}+\mathrm{I}, 05 \mathrm{X}_{4}$ 
$\mathrm{X}_{6}=$ Current Liabilities/Total Asset

$\mathrm{X}_{7}=\log ($ Fixed Asset $)$

$\mathrm{X}_{8}=$ Working Capital $/$ Total

Liabilities

$\mathrm{X}_{9}=\log (\mathrm{EBIT}) /$ Interest Expense

Kriteria analisisya adalah, jika :

$\mathrm{H}<0$ diprediksi mengalami

kebangkrutanatau kondisi

perusahaan tidak sehat

$\mathrm{H}>0$ diprediksi kondisi perusahaan

Dalam keadaan baik atau sehat

\section{Model PrediksiSpringate}

Model Springate ditemukan oleh Gordon L.V. Springate pada tahun I978 sebagai pengembangan dari model Altman dalam memprediksi kebangkrutan. Menurut Rudianto dalam Norita (20I5) Springate Score merupakan model untuk memprediksi keberlangsungan hidup suatu perusahaan dengan mengkombinasikan beberapa rasio keuangan dengan memberikan bobot yang berbeda diantara rasio tersebut. Rumus dari model ini adalah sebagai berikut :

$\mathrm{S}=\mathrm{I}, 03 \mathrm{X}_{\mathrm{I}}+3,07 \mathrm{X}_{2}+0,66 \mathrm{X}_{3}+$ $0,40 \mathrm{X}_{4}$

Dimana:

$\mathrm{X}_{\mathrm{I}}=$ Working Capital/Total Asset

$\mathrm{X}_{2}=\mathrm{EBIT} /$ Total Asset

$\mathrm{X}_{3}=\mathrm{EBT} /$ Current Liability

$\mathrm{X}_{4}=$ Sales/Total Asset

Kriteria analisisnya adalah, jika :

S>0,862 : perusahaan dalam kondisi

Sehat atau tidak berpotensi mengalami kebangkrutan $\mathrm{S}<0,862$ :perusahaan berpotensi

Mengalami kebangkrutan

\section{3) Opini Auditor}

Menurut Agoes dalam Norita (2016:8), pada akhir pemeriksaannya, auditor akan memberikan penilaiannya mengenai kewajaran laporan keuangan, yang akan diberikan dalam bentuk opini. Opini auditor menjadi terjemahan laporan keuangan yang digunakan oleh pengguna laporan keuangan dalam mengambil keputusan. Menurut Standar Profesi Akuntan Publik (SPAP), opini audit ada 5 macam yaitu :

I. Opini wajar tanpa pengecualian menyatakan bahwa laporan keuangan disajikan secara wajar sesuai dengan prinsip akuntansi

2. Opini wajar tanpa pengecualian dengan paragraf penjelasan yang ditambahkan dalam laporan audit bentuk baku (Unqualified Opinion With Explanatory Language)

3. Opini Wajar Dengan Pengecualian (Qualified Opinion)

4. Opini Tidak Wajar (Adverse Opinion)

5. Pernyataan Tidak Memberikan Opini (Disclaimer Opinion)

Arens et al. (2008:58) menyatakan bahwa laporan audit adalah tahap terakhir dari keseluruh proses audit. Dengan demikian auditor dalam memberikan opini sudah didasarkan pada keyakinan profesionalnya. Opini audit merupakan pernyataan atas suatu asersi yang dikeluarkan oleh auditor. Opini harus didasarkan atas pemeriksaan yang dilaksanakan sesuai 
dengan norma pemeriksaan akuntan dan atas temuan-temuannya. Hasil pemeriksaan akuntan tertuang dalam suatu laporan yang menyatakan bahwa apakah laporan keuangan telah disajikan secara wajar sesuai dengan prinsip akuntansi yang berlaku umum.

\section{PenelitianTerdahulu}

a. Syaiful Bahri dan Nurul Widyawati (20I5) meneliti prediksi kebangkrutan dengan judul "Analisis Prediksi Kebangkrutan Pada Perusahaan Yang Di Delisting Di Bursa Efek Indonesia. Objek penelitian adalah perusahaanperusahaan yang di delisting pada tahun 20I3. Metode yang digunakan adalah model Altman Z Score. Hasil Penelitian menunjukkan bahwa PT. Cipendewa diprediksi mengalami kebangkrutan, PT. Indosiar Karya Medika berada pada kondisi rawan bangkrut, sedangkan PT. Surabaya Agung Industri dan PT. Wiratama Sakti berada pada kondisi bangkrut.

b. Dita Wisnu Safitri (2015) melakukan penelitian yang berjudul "Analisis Prediktor Kebangkrutan Terbaik Dengan Menggunakan Metode Altman, Springate dan Zmijeski Pada Perusahaan Delisting Dari Bursa Efek Tahun 2012. Tujuan penelitian untuk mengetahui seberapa efektif penggunaan metode Altman, Springate, dan Zmijewski sebagai predictor terbaik dalam menganalisis perusahaan yang telah di delisting pada tahun 2012. Hasil penelitian menunjukkan bahwa metode Altman merupakan metode yang paling efektif digunakan untuk memprediksi perusahaan yang telah di delisting.

c. Reza Prabowo dan Wibowo (20I5) meneliti prediksi kebangkrutan dengan judul "Analisis Perbandingan Model Altman Z-Score, Zmijewski, dan Springate dalam Memprediksi Kebangkrutan Perusahaan Delisting Di BEI Periode 2008-20I3. Metode yang digunakan adalah Altman, Zmijewski dan Soringate. Hasil penelitian mengindikasikan Model Altman adalah predictor terbaik umtuk memprediksi perusahaan delisting dengan tingkat akurasi $71 \%$.

d. Selmy (20) Results and conclusions are bankruptcy analysis using the Altman Z-score model of PT. Gudang Garam Tbk. for the period 2008-20II is in a position of the healthy company. While in 2012 the company touched the position of grey area and the Springate models classified the company not potentially bankrupt. Based on the analysis results by using the Altman Z-score and Springate models, it can be seen that the liquidity and inefficient management extremely 
affect to financial performance of the company.

e. Wang and Campbell (2010) : All three models were found tohave significant predictive ability. The reestimated model has higherprediction accuracy for predicting nonfailed firms, but Altman's model hashigher prediction accuracy for predicting failed firms. The revised Zscoremodel has a higher prediction accuracy compared with both the reestimated model and Altman's original model. This study indicates that the Z-score model is a helpful tool in predicting failure of a publicly listed firm in China.

f. Kokyung and Khairani (2013) : The results showed that the method of Altman Zscore and Springate able to predict the potential bankruptcy of the PT. Bakrie Telecom Tbk in 2009 -20I2, where the Altman Z-score method and Springate detect that there has been a signi ficant decline in performance on PT.Bakrie Telecom Tbk. There are differences between the results predicted bankruptcy Altman Zscore method and Springate because of differences in the use of financial ratios and bankruptcy criteria between the Altman Z-score and Springate.

g. SuryantoTulus (2016) This study examinesthe relationship between
Islamic work ethics and auditors' opinion, focusing onthe aspects of audit professionalism and dysfunctional behavior as interveningvariables. The research involved in Internal Auditors working of Islamic Bankingindustry in Sumatra Island. The results of the study confirmed the three hypothesesexamined: there is a positive corelation between Islamic work ethics and auditors'opinions; auditors' professionalism is an intervening variable of the correlationbetween Islamic work ethics and auditors' opinions and dysfunctional behavioris a negative intervening variable of the correlation between Islamic Work Ethicsand auditors' opinions.

\section{METODE PENELITIAN}

Penelitian ini merupakan penelitian deskriptif kuantitatif dimana rumusan masalah digambarkan secara deskriptif sedangkan data yang digunakan adalah data kuantitaif. Penelitian deskriptif adalah penelitian yang berkenan dengan pertanyaan terhadap keberadaan variabel mandiri, baik hanya pada satu variabel atau lebih. (Sugiyono, 2010:35).

Sedangkan menurut Sekaran, (2006:158), penelitian deskriptif adalah penelitian yang dilakukan untuk menjelaskan karakteristik-karakteristik yang diteliti dalam suatu situasi. Dalam penelitian ini penelitian deskriptif dilakukan untuk mengetahui prediksi 
kebangkrutan perusahaan dengan menggunakan model Altman, Fulmer danSpringate.

\section{Populasi}

Menurut Sugiyono (2010:80) populasi adalah wilayah generalisasi yang terdiri atas obyek/subyek yang memiliki kualitas dan karakteristik tertentu yang ditetapkan oleh peneliti untuk dipelajari dan kemudian ditarik kesimpulannya. Populasi dalam penelitian ini adalah perusahan-perusahaan yang delisting dari Bursa Efek Indonesia pada tahun 2015 yaitu PT. Bank Ekonomi Raharja, PT. Davomas Abadi dan PT. Unitex.

\section{Sample}

Menurut Sugiyono (2010:8I), sampel adalah bagian dari jumlah dan karakteristik yang dimiliki oleh populasi. Sedangkan teknik sampling adalah merupakan teknik pengambilan sampel mana yang akan digunakan dalam penelitian.

Dalam penelitian ini teknik pengambilan sampel yang dilakukan adalah dengan teknik purposive sampling, di mana mengambil sampel berdasarkan kriteria.

Adapun kriteria yang ditentukan dalam penelitian ini adalah perusahaan yang memiliki laporan keuangan dari tahun 20II-20I5 dan masih di publish meskipun sudah di delisting dari bursa efek.

Oleh karena itu sample pada peneltian ini adalah PT. Bank Ekonomi Raharja dikarenakan laporan keuangan perusahaan tersebut masih ter-publish dari tahun 20II-20I5.

\section{HASIL DAN PEMBAHASAN}

\section{Altman Z-Score}

Berdasarkan hasil pengolahan data pada laporan keuangan PT. Bank Ekonomi pada tahun 20II-20I5 dimana pada periode tersebut perusahaan masih listing di bursa efek maka diperoleh hasil prediksi kebangkrutan metode Altman Z-Score yang disajikan pada Tabel I berikut ini :

Tabel 1

Hasil Perhitungan Altman Z-Score

\begin{tabular}{|l|l|l|l|l|l|l|}
\hline \multirow{2}{*}{ Tahun } & $\mathrm{X} 1$ & $\mathrm{X} 2$ & $\mathrm{X} 3$ & $\mathrm{X} 4$ & \multirow{2}{Z}{$\begin{array}{l}\text { Z- } \\
\text { Score }\end{array}$} & $\begin{array}{l}\text { Kategori } \\
\text { Z-Score }\end{array}$ \\
\hline & 6.56 & 3.26 & 6.72 & 1.05 & Scon \\
\hline 2011 & 0.1028 & 0.0836 & 0.0408 & 0.1180 & 1.3447 & Grey Zone \\
\hline 2012 & 0.1032 & 0.0851 & 0.0394 & 0.1183 & 1.3436 & Grey Zone \\
\hline 2013 & 0.1153 & 0.0850 & 0.0421 & 0.1154 & 1.4378 & Grey Zone \\
\hline 2014 & 0.1291 & 0.0846 & 0.0469 & 0.1132 & 1.5566 & Grey Zone \\
\hline 2015 & 0.1754 & 0.0837 & 0.0491 & 0.1678 & 1.9294 & Grey Zone \\
\hline
\end{tabular}

Kriteria penilaian kategori perusahaan berdasarkan model Altman Z-Score adalah ketika nilai $Z \geq 2,6$ dinyatakan tidak bangkrut atau dalam kondisi sehat, jika I,IO $\leq \mathrm{Z} \leq 2,6$ dinyatakan kategori grey zone dan jika $\mathrm{Z} \leq \mathrm{I}, \mathrm{I0}$ dinyatakan kategori bangkrut.V.




Berdasarkan hasil pengolahan data keuangan perusahaan yang ditampilkan pada tabel 2 dapat dilihat bahwa keadaan perusahaan sebelum di delisting dari bursa efek diprediksi berada pada area grey zone.Hal ini sesuai dengan kondisi perusahaan yang sampai saat ini masih mampu menjalankan kegiatan bisnisnya.

\section{Fulmer}

Berdasarkanhasilpengolahan data laporan keuangan PT. Bank Ekonomi Raharja pada tahun 20II-20I5 yang disajikan pada tabel 2, dapat dilihat bahwa dengan nilai kriteria prediksi kebangkrutan model Fulmer dimana ketika nilai $\mathrm{H}<0$ diprediksi mengalami kebangkrutan atau kondisi perusahaan tidak sehat, sedangkan jika $\mathrm{H}>0$ diprediksi kondisi perusahaan dalam keadaan baik atau sehat. Dari hasil

Analisis perhitungan dapat dilihat nilai H-Score PT. Bank Ekonomi Raharja dari tahun 20II-20I6 berada dibawah 0 (nol), hal ini mengindikasikan bahwa sebelum di delisting oleh bursa perusahaan diprediksi akan mengalami kebangkrutan. Hal ini sesuai dengan opini dari pihak PT. Bank Ekonomi Raharja yang menyatakan bahwa harga saham perusahaan terus mengalami penurunan dan sebagian besar jumlah saham dimiliki oleh HSBC Group.

\section{Springate}

Dari hasil perhitungan pada analisis laporan keuangan PT. Bank Ekonomi Raharja periode 20II-20I5 yang disajikan pada tabel 3, dapat dilihat berdasarkan kriteria kategorisasi model Springate $S>0,862$ perusahaan dalam kondisi sehat atau tidak berpotensi mengalami kebangkrutan, jika $\mathrm{S}<$ 0,862 perusahaan berpotensi mengalami kebangkrutan.

Dari hasil analisis pada pengolahan data diperoleh hasil bahwa dari tahun 20I I-20I5 PT. Bank Ekonomi Raharja diprediksi mengalami kebangkrutan.

\section{Kesesuaian Dengan Opini Auditor}

\section{Kondisi Perusahaan MenurutOpini} Auditor PadaTahun 20II

Tabel 3

Hasil Perhitungan Springate

\begin{tabular}{|c|c|c|c|c|c|c|}
\hline \multirow{2}{*}{ Tahun } & X1 & X2 & X3 & X4 & S- & Kategori \\
\cline { 2 - 7 } & 1.03 & 3.07 & 0.66 & 0.4 & Score & S-Score \\
\hline 2011 & 0.103 & 0.041 & 0.015 & 0.042 & 0.258 & Bangkrut \\
\hline 2012 & 0.103 & 0.039 & 0.011 & 0.045 & 0.252 & Bangkrut \\
\hline 2013 & 0.115 & 0.042 & 0.013 & 0.045 & 0.275 & Bangkrut \\
\hline 2014 & 0.129 & 0.047 & 0.003 & 0.036 & 0.294 & Bangkrut \\
\hline 2015 & 0.175 & 0.049 & 0.001 & 0.035 & 0.346 & Bangkrut \\
\hline
\end{tabular}

Sumber: Data Diolah

"Menurut pendapat kami, informasi keuangan yang tercantum dalam laporan posisi keuangan tanggal 3I Desember $20 I I$ disajikan secara wajar, dalam semua hal yang material dalam hubungannya dengan laporan posisi keuangan sesuai dengan sumber acuannya”.

\section{Kondisi Perusahaan MenurutOpini Auditor Pada Tahun 2012}

"Menurut pendapat kami, laporan keuangan yang kami sebut di atas menyajikan secara wajar, dalam semua hal yang material, posisis keuangan PT. 
Bank Ekonomi Raharja, Tbk. Pada tanggal 3I Desember 20I2, 3 I Desember 20I I dan I Januari 20II, dan hasil usaha serta arus kas untuk tahun yang berakhir pada tanggal 3I Desember 2012 dan 20II sesuai dengan Standar Akuntansi Keuangan di Indonesia.

Seperti yang diungkapkan pada catatan 2e atas laporan keuangan, mulai tanggak I Januari 2012 Bank telah menerapkan Pernyataan Standar Akuntansi Keuangan ("PSAK") tertentu yang berlaku efektif sejak tanggal I Januari 2012 secara prospektif'.

\section{Kondisi Perusahaan MenurutOpini} Auditor Pada Tahun 2013

"Menurutopini kami, laporan keuangan terlampir menyajikan secara wajar, dalam semua hal yang material, posisi keuangan PT. Bank Ekonomi Raharja Tbk tanggal 3I Desember 2013, serta kinerja keuangan dan arus kasnya untuk tahun yang berakhir pada tanggal tersebut, sesuai dengan Standar Akuntansi Keuangan di Indonesia”.

\section{Kondisi Perusahaan Menurut Opini Auditor Pada Tahun 2014}

"Menurut opini kami, laporan keuangan terlampir menyajikan secara wajar, dalam semua hal yang material, posisi keuangan PT. Bank Ekonomi Raharja Tbk tanggal 3I Desember 20I4, serta kinerja keuangan dan arus kasnya untuk tahun yang berakhir pada tanggal tersebut, sesuai dengan Standar Akuntansi Keuangan di Indonesia”.

\section{Kondisi Perusahaan MenurutOpini Auditor Pada Tahun 2015}

"Menurutopini kami, laporan keuangan terlampir menyajikan secara wajar, dalam semua hal yang material, posisi keuangan PT. Bank Ekonomi RaharjaTbk tanggal 3I Desember 20I4, serta kinerja keuangan dan aruskasnya untuk tahun yang berakhir pada tanggal tersebut, sesuai dengan Standar Akuntansi Keuangan di Indonesia".

Presentase Kesesuaian Metode Altman, Fulmer dan SpringateTerhadapOpini Auditor

Tabel 4

Hasil Perhitungan Springate

\begin{tabular}{|c|c|c|c|c|}
\hline Tahun & Altman & Fulmer & Springate & Opini Auditor \\
\hline 2011 & Grey Area & Bangkrut & Bangkrut & UO \\
\hline 2012 & Grey Area & Bangkrut & Bangkrut & UOWEL \\
\hline 2013 & Grey Area & Bangkrut & Bangkrut & U0 \\
\hline 2014 & Grey Area & Bangkrut & Bangkrut & U0 \\
\hline 2015 & Grey Area & Bangkrut & Bangkrut & UO \\
\hline \multicolumn{4}{|c|}{ Total } & 5 \\
\hline \multicolumn{4}{|c|}{ Kesesuaian } & $20 \%$ \\
\hline \multicolumn{4}{|c|}{ Ketidaksesuaian } & $80 \%$ \\
\hline
\end{tabular}

Sumber: Data Diolah

Berdasarkanhasilanalisiskebangkruta n dengan menggunakanmodel Altman, Fulmer dan Springate dengan opini yang diberikan auditor pada laporan keuangan diperoleh hasil tingkat kesesuaian antara hasil prediksi dengan opini auditor yang disajikan pada tabel 4 dibawah ini :

Keterangan :

UO :OpiniWajar Tanpa Pengecualian UOwEL: Opini Wajar Tanpa Pengecualian dengan Paragraf Penjelas 
Dari tabel 4 dapat dilihat bahwa ketiga model memprediksi perusahaan mengalami masalah keuangan atau financial distress. Pada model Altman perusahaan dikategorikan pada grey zone, kondisi ini mengindikasikan bahwa perusahaan belum mengalami kebangkrutan tetapi berdasarkan kriteria opini auditor perusahaan digolongkan kedalam kondisi bangkrut, sedangkan dua model lainnya yaitu fulmer dan springate menggolongkan perusahaan mengalami kebangkrutan.

Jika dilihat melalui opini auditor selama lima tahun terakhir sebelum delisting yaitu tahun 20II-20I5 hanya pada tahun 2012 opini auditor yang menyatakan wajar tetapi dengan paragraph penjelas (UOwEL) dan opini tersebut sesuai dengan kondisi perusahaan pada tahun 2012 yang mengalami financial distress sehingga diprediksi mengalami kebangkrutan. Sedangkan selain tahun 2012 opini auditor menyatakan wajar dan hal tersebut tidak sesuai dengan hasil prediksi kebangkrutan. Sehingga dapat disimpulkan bahwahsanya $20 \%$ tingkat kesesuaian antara model prediksi kebangkrutan Altman, Fulmer dan Springate yang sesuai dengan opini auditor.

\section{SIMPULAN}

I. Model Altman menyatakan perusahaan dalam area "grey zone" dimana pihak manajemen harus berhati-hati dengan kondisi tersebut karena kondisi tersebut lebih cenderung memprediksi mengalamai kebangkrutan dibandingkan kondisi perusahaan yang sehat. Sedangkan model Fulmer dan Springate menyatakan selama lima tahun terakhir sebelum delisting perusahaan mengalami kebangkrutan Dari hasil tersebut model Altman lebih efektif dalam memprediksi kebangkrutan dikarenakan sampai saat ini PT. Bank Ekonomi Raharja masih beroperasi hanya saja harus meningkatkan kinerja agar tidak mengalami kebangkrutan.

2. Ada perbedaan hasil prediksi dari ketiga model dimana model Altman menyatakan perusahaan dalam area "grey zone" sedangkan model Fulmer dan Springate menyatakan bangkrut.

3. Tingkat kesesuaian antara prediksi kebangkrutan model Altman, Fulmer dan Springate dengan opini auditor hanya sebesar $20 \%$

\section{DAFTAR PUSTAKA}

Altman, Edward I. 1968. Discriminant Analysis and the Prediction of Corpor. Bankruptcy. The Journal of Finance, Vol. 23, No. 4. (Sep., I968), pp 5\& 154 609.

Bahri, Syaiful. 2015. Analisis Prediksi Kebangkrutan Pada Perusahaan Yang DiDelisting Di Bursa Efek Indonesia. Jurnal Ilmu dan Riset Manajemen Vol. 4 No. 8

Fatmawati, Mila. 2012. Penggunaan The Zmijewski Model, The Altman Model, Dan The Springate Model Sebagai Prediktor Delisting. Jurkubank Vol. I6 No. I

Husnan, Suad. Dan Enny Pudjiastuti. (2006). Dasar- Dasar Manajeman Keuangan. Yogyakarta, UPP STIM YKPN.

Kokyung and Siti Khairani. 2013. Analisis Penggunaan Altman Z-score dan Springate untuk Mengetahui Bancruptcy Potential pada PT.Bakrie Telecom Tbk. Palembang : STIE MDP. 
Norita. 2015. Analisis Bancruptcy Potential Perusahaan Vendor Telekomunikasi Berdasarkan Rasio Keuangan Bermasalah Dengan Metode Altman, Springate Dan Zmijewski (Studi Pada Nokia Corporation). Bandung : Universitas Telkom.

Prabowo, Reza danWibowo. 2015. Analisis Perbandingan Model Altman Z-Score, Zmijewski, dan Springate dalam Mempredikso Kebangkrutan Perusahaan Delisting Di BEI Periode 2008-2013. Jurnal Akuntansi, Keuangan, dan Perbankan Vol. I No. 3. Jakarta : Politeknik Jakarta

Puspitaningrum, Titisdan Linda Purnamasari. 20I6. Analisis Prediktor Delisting Terbaik (Perbandingan Antara Model Zmijewski, Model Altman, Model Springate). Jurnal Buletin Studi Ekonomi Vol 2I No. I

Robot, Selmy. 2013. The Application Of Bankruptcy Prediction Analysis Using Altman Z-Score And Springate Methods At Pt. Gudang Garam Tbk. Manado : Universitas Samratulangi. Vol. I pg. 630-636

Savitri, DitaWisnu. 2015. Analisis Prediktor Kebangkrutan Terbaik Dengan Menggunakan Metode Altman, Springate Dan Zmijewski Pada Perusahaan Delisting Dari Bursa Efek Indonesia Tahun 2012. Bandung : Universitas Telkom

Sekaran, Uma. (2006). Metodologi Penelitian untuk Bisnis Edisi Keempat.Jakarta: Salemba Empat.

Sugiyarso, G. dan F. Winarni. (2005). Manajemen Keuangan:Pemahaman Laporan Keuangan, Pengelolaan Aktiva, Kewajiban dan Modal, serta Pengukuran Kinerja Perusahaan, Yogyakarta, Media Pressindo.

Sugiyono. (2010). Metode Penelitian Kuantitatif, Kualitatif, dan $R$ \& D. Bandung :Alfabeta

Suryanto, T., 2016. Islamic Work Ethics and Audit Opinions: Audit Professionalism and Dysfunctional Behavior as Intervening Variables. AlIqtishad: Journal of Islamic Economics, 8(I), pp.49-64.

Syafitri, Lili and Trisnadi Wijaya. 20I4. Analisis Komparatif Dalam Memprediksi Kebangkrutan Pada Pt. Indofood Sukses Makmur Tbk.Palembang : STIE MDP.

Tambunan, Rafles W.,dkk. 20I5. Analisis Predikso Kebangkrutan Perusahaan Dengan Menggunakan Metode Altman Z-Score. Jurnal Administrasi Bisnis Vol. 2 No. I

Suryanto, T. (2015). Internal Control, Discipline Of Its Impact On Emplovee Performance: Case Studv On Islam Institute State RadenIntan Lampung, Indonesia. ProsidingSembistek 20I4, I(OI), 325-339.

Venkataramana, N., etc. 20I2. Financial Performance And Predicting The Risk Of Bankruptcy: A Case Of Selected Cement Companies In India. International Journal Of Public Administration And Management Research (IJPAMR), Vol. I pg. 40-56.

Wachowicz, John M, Jr. dan James C Van Horne. (2005). Prinsip-prinsip Manajemen Keuangan, Jakarta, Salemba Empat.

Wang, Ying and Michael Campbell. 2010. Business Failure Prediction for Publicly Listed Companies in China. Journal of Business and Management. Vol. I6, No. I, pg. 75. www.investasi.kontan.co.id 